\title{
Parametric Sensitivity Analysis of a Mathematical Model of Two Interacting Populations of Technologies: Part II
}

\author{
${ }^{1}$ Enu Ekaka-a, ${ }^{2}$ E. C. Nwachukwu, ${ }^{3}$ Jacreece Prebo Clifford, \\ Department of Mathematics and Statistics, University of Port Harcourt, P.M.B. 5323, Port Harcourt, Nigeria \\ Department of Mathematics and Statistics, University of Port Harcourt, P.M.B. 5323, Port Harcourt, Nigeria \\ Department of Mathematics and Statistics, University of Port Harcourt, P.M.B. 5323, Port Harcourt, Nigeria \\ N. M. Nafo, \\ Department of Mathematics and Computer Science, Rivers State University of Science and Technology, Port \\ Harcourt, Rivers State, Nigeria
}

\begin{abstract}
Experts in the mathematical modeling for two interacting technologies have observed the different contributions between the intraspecific and the interspecific coefficients in conjunction with the starting population sizes and the trading period. In this complex multi-parameter system of competing technologies which evolve over time, we have used the numerical method of mathematical norms to measure the sensitivity values of the intraspecific coefficients $b$ and e, the starting population sizes of the two interacting technologies and the duration of trading. We have observed that the two intraspecific coefficients can be considered as most sensitive parameter while the starting populations are called least sensitive. We will expect these contributions to provide useful insights in the determination of the important parameters which drive the dynamics of the technological substitution model in the context of one-at-a-timesensitivity analysis.

Keywords: Sensitivity Analysis, Mathematical Model, Interacting Technologies.
\end{abstract}

Accepted Date: 04 June 2013

\section{Introduction}

Following Bazykin [1], we will consider this specific system of model continuous non-linear first order ordinary differential equations of the Lotka-Volterra type such as :

$\frac{d x_{1}}{d t}=\frac{a_{1} x_{1}}{k_{1}}\left(k_{1}-x_{1}-\alpha_{2} x_{2}\right)$

$\frac{d x_{2}}{d t}=\frac{a_{2} x_{2}}{k_{2}}\left(k_{2}-x_{2}-\alpha_{1} x_{1}\right)$

such that $x_{1}(0)=x_{10}>0$ and $x_{2}(0)=x_{20}>0$.

where $x_{1}$ and $x_{2}$ are the populations of technology 1 and technology 2 respectively, $a_{1}$ and $a_{2}$ specify the intrinsic growth rates of technologies 1 and 2 respectively in the absence of both interspecific and intraspecific coefficient, $\alpha_{1}$ and $\alpha_{2}$ specify the interspecific coefficients of competition between technologies 1 and technology 2. In this scenario, $k_{1}$ and $k_{2}$ specify the market size of technologies 1 and 2 which otherwise can be considered as the carrying capacities of technologies 1 and 2 respectively.

In our previous analysis which has been accepted for publication by the Journal of Nigerian Association of Mathematical Physics (Vol 28), we studied the sensitivity of the intrinsic growth rates, for technology 1 and technology 2 followed by the sensitivity analysis of the starting population sizes of technology 1 and technology 2 . The sensitivity analysis of the duration of trading in the unit of years was considered.

In the present contribution, we are interested to study the sensitivity behaviour of the intraspecific coefficients, the starting population sizes and duration of trading between technology 1 and technology 2 .

Several other researchers such as Kumar and Kumar [2], Young [3], Bhargava [4] and Morris and Pratt [5] have considered interesting aspects of the theoretical formulation and mathematical analysis of the popular technology substitution model. Irrespective of their several contributions to knowledge with respect to further extensions of technological substitution model, the open problem of studying the sensitivity of the intraspecific coefficients and the starting populations for the two interacting technologies remains to be fully tackled numerically. It is against this motivation that we are proposing to adapt the standard method of one-at-a-time sensitivity analysis as currently proposed and applied in the work of Ekaka-a [6]. 


\section{Mathematical Formulation}

Following Morris and Pratt [5] we recast equations (1) and (2) in the following form

$$
\begin{aligned}
& \frac{d x_{1}}{d t}=\left(a x_{1}-b x_{1}^{2}-c x_{1} x_{2}\right) \\
& \frac{d x_{2}}{d t}=\left(d x_{2}-e x_{2}^{2}-f x_{2} x_{1}\right)
\end{aligned}
$$

In this paper, $a$ and $d$ arecalled the intrinsic growth rates of technology 1 and technology $2, b$ and $e$ are called the intraspecific coefficients of technology 1 and technology 2 while $c$ and $f$ are called the interspecific coefficients of technology 1 and technology 2.

Comparing the model equations(1), (2), (3) and (4), it is clear that

$$
a=a_{1}, \quad b=\frac{a_{1}}{k_{1}}, c=\frac{a_{1} \alpha_{2}}{k_{1}}, \quad d=a_{2}, e=\frac{a_{2}}{k_{2}}, f=\frac{a_{2} \alpha_{1}}{k_{2}}
$$

On the basis of these transformation formulae, it follows that

$$
\gamma=1.0=\frac{a_{2}}{a_{1}} \text { implies that } a_{1}=a_{2} \text {. Therefore, } a=a_{1}=a_{2}=d \text {. Hence, } a=d .
$$

In this scenario, we have chosen the values of $a$ and $d$ to be 0.12 . The same assumption can be invoked for the intraspecific coefficients $b$ and $e$ such that $b$ will have the value 0.012 and $e$ will have the value of 0.012 . Since we are considering a system of Lotka-Volterra type, we also assume that the interspecific coefficients must be smaller than the intraspecific coefficients. This assumption is consistent with recent research report of Ekaka-a [6]. It is against this background that we have chosen the values of $c$ and $f$ to be 0.0048 and 0.0096 respectively. Therefore, $a=0.12, b=0.012, c=0.0048, d=0.12, e=0.012, f=0.0096$.

\section{Materials and methods}

The key steps of the one-at-a-time sensitivity analysis have been clearly defined, explained and illustrated in our previous paper which has been accepted for publication in Journal of Nigeria Association of Mathematical Physics (Vol. 28) and Ekaka-a [6].

\section{Discussion of results}

In this present study, we will present the sensitivity measures of parameters $b, e, x_{1}(0), x_{2}(0)$ and the duration $\mathrm{T}$. Table 1 presents the sensitivity values of these parameters due to $1 \%$ variation of each parameter when other parameters are fixed. What do we learn from table 1? It is very clear from table 1 that the intraspecific coefficient $\mathrm{e}$ is a dominant most sensitive parameter followed by intraspecific coefficient $\mathrm{b}$ which can also be considered as a relatively next most sensitive parameter. The next sensitive parameter with a lower sensitivity value concerns the duration of trading period $T$. In the context of this analysis, the two starting populations can be considered as least sensitive especially when the 1-norm and 2-norm numerical methods of calculating their parameter sensitivity were implemented. Since the three most popular mathematical norms are useful in measuring the extent of error analysis in collected data, we will consider the higher sensitivity values to reflect larger deviations between the simulated data and the modified simulated data (due to the variation of a model parameter one-at-a-time when other parameters are fixed) while the least sensitive parameter indicate and smaller deviations between these two sets of simulated data. Similar observations which we cannot provide detailed explanations extend to $2 \%$ variation of model parameter sensitivity as displayed in Table 2, $3 \%$ variation of model parameter sensitivity as displayed in Table 3 and so forth up till $10 \%$ variation of model parameter sensitivity as displayed in Table 10 .

\begin{tabular}{|c|c|c|c|c|c|c|c|c|c|c|c|}
\hline $\mathrm{mp}$ & $\mathrm{b}$ & $\mathrm{e}$ & $\mathrm{x}_{1}(0)$ & $\mathrm{x}_{2}(0)$ & $\mathrm{T}$ & \multicolumn{5}{|c|}{ Order of sensitivity } & $\mathrm{E}_{\mathrm{S}}$ \\
\hline 1-norm & 11224 & 32933 & 5.94 & 5.96 & 119.40 & $\mathrm{e}$ & b & $\mathrm{T}$ & $\mathrm{x} 2(0)$ & $\mathrm{x} 1(0)$ & 5542 \\
\hline 2-norm & 11189 & 32930 & 24.01 & 24.31 & 91.79 & $\mathrm{e}$ & $\mathrm{b}$ & $\mathrm{T}$ & $\mathrm{x} 2(0)$ & $\mathrm{x} 1(0)$ & 1371 \\
\hline infinity-norr & 11312 & 17668 & 166.22 & 123.20 & 149.91 & $\mathrm{e}$ & b & $\mathrm{x} 1(0)$ & $\mathrm{T}$ & $\mathrm{x} 2(0)$ & 143.4 \\
\hline
\end{tabular}

The parameter values for this group are:

$$
\begin{array}{llll}
\mathrm{b}=0.012 & \mathrm{e}=0.012 & \mathrm{x}_{1}(0)=1 & \mathrm{~T}=10 \text { years }
\end{array}
$$

Table 1: $1 \%$ variation of model parameters

Table 2: $2 \%$ variation of model parameters

\begin{tabular}{|l|l|l|l|l|l|l|l|l|l|l|l|}
\hline $\begin{array}{l}\mathrm{mp} \\
\mathrm{mn}\end{array}$ & $\mathrm{b}$ & $\mathrm{e}$ & $\mathrm{x}_{1}(0)$ & \multicolumn{2}{l|}{$\mathrm{x}_{2}(0)$} & $\mathrm{T}$ & \multicolumn{3}{l|}{ Order of sensitivity } & & $\mathrm{E}_{\mathrm{S}}$ \\
\hline 1-norm & 5620.2 & 16492 & 5.09 & 5.08 & 94.68 & $\mathrm{e}$ & $\mathrm{b}$ & $\mathrm{T}$ & $\mathrm{x} 1(0)$ & $\mathrm{x} 2(0)$ & 3244 \\
\hline 2-norm & 5549.6 & 16429 & 20.99 & 22.13 & 77.4 & $\mathrm{e}$ & $\mathrm{b}$ & $\mathrm{T}$ & $\mathrm{x} 2(0)$ & $\mathrm{x} 1(0)$ & 782.4 \\
\hline infinity-norm & 5651.3 & 8858 & 153.02 & 119.35 & 147.00 & $\mathrm{e}$ & $\mathrm{b}$ & $\mathrm{x}_{1}(0)$ & $\mathrm{T}$ & $\mathrm{x}_{2}(0)$ & 74.21 \\
\hline
\end{tabular}


Table3: $3 \%$ variation of model parameters

\begin{tabular}{|l|l|l|l|l|l|l|l|l|l|l|l|l|}
\hline $\begin{array}{l}\mathrm{mp} \\
\mathrm{mn}\end{array}$ & $\mathrm{b}$ & $\mathrm{e}$ & $\mathrm{x} 1(0)$ & $\mathrm{x} \mathrm{x}_{2}(0)$ & $\mathrm{T}$ & \multicolumn{3}{|l|}{ Order of sensitivity } & \multicolumn{2}{l|}{$\mathrm{E}_{\mathrm{S}}$} \\
\hline 1-norm & 3749.9 & 11004 & 4.57 & 4.56 & 72.11 & $\mathrm{e}$ & $\mathrm{b}$ & $\mathrm{T}$ & $\mathrm{x} 1(0)$ & $\mathrm{x} 2(0)$ & 2414 \\
\hline 2-norm & 3668.9 & 10924 & 19.13 & 20.67 & 64.70 & $\mathrm{e}$ & $\mathrm{b}$ & $\mathrm{T}$ & $\mathrm{x} 2(0)$ & $\mathrm{x} 1(0)$ & 570.8 \\
\hline infinity-norm & & & & & & & & & & & \\
& 3764 & 5921 & 143.78 & 115.79 & 144.34 & $\mathrm{e}$ & $\mathrm{b}$ & $\mathrm{T}$ & $\mathrm{x} 1(0)$ & $\mathrm{x} 2(0)$ & 51.13 \\
\hline
\end{tabular}

Table 4: 4\% variation of model parameters

\begin{tabular}{|l|l|l|l|l|l|l|l|l|l|l|l|l|}
\hline $\begin{array}{l}\mathrm{mp} \\
\mathrm{mn}\end{array}$ & $\mathrm{b}$ & $\mathrm{e}$ & $\mathrm{x}(0)$ & $\mathrm{x} 2(0)$ & $\mathrm{T}$ & \multicolumn{3}{|l|}{ Order of sensitivity } & $\mathrm{E}_{\mathrm{S}}$ \\
\hline 1-norm & 2813.9 & 8258.3 & 4.20 & 4.19 & 56.92 & $\mathrm{e}$ & $\mathrm{b}$ & $\mathrm{T}$ & $\mathrm{x} 1(0)$ & $\mathrm{x} 2(0)$ & 1971 \\
\hline 2-norm & 2728.4 & 8171.4 & 17.77 & 19.54 & 56.26 & $\mathrm{e}$ & $\mathrm{b}$ & $\mathrm{T}$ & $\mathrm{x} 2(0)$ & $\mathrm{x} 1(0)$ & 459.7 \\
\hline infinity-norm & & & & & & & & & & & \\
& 2820.3 & 4453.2 & 136.43 & 112.48 & 141.81 & $\mathrm{e}$ & $\mathrm{b}$ & $\mathrm{T}$ & $\mathrm{x} 1(0)$ & $\mathrm{x} 2(0)$ & 39.58 \\
\hline
\end{tabular}

Table 5: 5\% variation of model parameters

\begin{tabular}{|c|c|c|c|c|c|c|c|c|c|c|c|}
\hline $\mathrm{mp}$ & $\mathrm{b}$ & $\mathrm{e}$ & $\mathrm{x}_{1}(0)$ & $\mathrm{x}_{2}(0)$ & $\mathrm{T}$ & & $\mathrm{or}$ & siti & & & $\mathrm{E}_{\mathrm{S}}$ \\
\hline 1-norm & 2252 & 6609.6 & 3.92 & 3.90 & 46.50 & $\mathrm{e}$ & $\mathrm{b}$ & $\mathrm{T}$ & $\mathrm{x} 1(0)$ & $\mathrm{x} 2(0)$ & 1693 \\
\hline 2-norm & 2164.1 & 6519 & 16.69 & 18.60 & 50.33 & $\mathrm{e}$ & $\mathrm{b}$ & $\mathrm{T}$ & $\mathrm{x} 2(0)$ & $\mathrm{x} 1(0)$ & 390.5 \\
\hline
\end{tabular}

Table 6: 6\% variation of model parameters

\begin{tabular}{|l|l|l|l|l|l|l|l|l|l|l|l|}
\hline $\begin{array}{l}\mathrm{mp} \\
\mathrm{mn}\end{array}$ & $\mathrm{b}$ & $\mathrm{e}$ & $\mathrm{x} 1(0)$ & $\mathrm{x} 2(0)$ & $\mathrm{T}$ & \multicolumn{3}{|l|}{ Order of sensitivity } & \multicolumn{2}{l|}{$\mathrm{E}_{\mathrm{S}}$} \\
\hline 1-norm & 1877.3 & 5509.9 & 3.68 & 3.67 & 39.08 & $\mathrm{e}$ & $\mathrm{b}$ & $\mathrm{T}$ & $\mathrm{x} 1(0)$ & $\mathrm{x} 2(0)$ & 1502 \\
\hline 2-norm & 1788 & 5417.3 & 15.79 & 17.80 & 45.89 & $\mathrm{e}$ & $\mathrm{b}$ & $\mathrm{T}$ & $\mathrm{x} 2(0)$ & $\mathrm{x} 1(0)$ & 343 \\
\hline infinity-norm & & & & & & & & & & & \\
& 1876.2 & 2984.9 & 124.87 & 106.42 & 136.95 & $\mathrm{e}$ & $\mathrm{b}$ & $\mathrm{T}$ & $\mathrm{x} 1(0)$ & $\mathrm{x} 2(0)$ & 28.04 \\
\hline
\end{tabular}

Table 7: 7\% variation of model parameters

\begin{tabular}{|l|l|l|l|l|l|l|l|l|l|l|l|}
\hline $\begin{array}{l}\mathrm{mp} \\
\mathrm{mn}\end{array}$ & $\mathrm{b}$ & $\mathrm{e}$ & $\mathrm{x}(0)$ & $\mathrm{x} \mathrm{x}_{2}(0)$ & $\mathrm{T}$ & \multicolumn{3}{|l|}{ Order of sensitivity } & \multicolumn{2}{l|}{$\mathrm{E}_{\mathrm{S}}$} \\
\hline 1-norm & 1609.4 & 4724.1 & 3.48 & 3.48 & 33.57 & $\mathrm{e}$ & $\mathrm{b}$ & $\mathrm{T}$ & $\mathrm{x} 1(0)$ & $\mathrm{x} 2(0)$ & 1358 \\
\hline 2-norm & 1519.4 & 4630.1 & 15.01 & 17.08 & 42.39 & $\mathrm{e}$ & $\mathrm{b}$ & $\mathrm{T}$ & $\mathrm{x} 2(0)$ & $\mathrm{x} 1(0)$ & 308.4 \\
\hline infinity-norm & & & & & & & & & & & \\
& 1606.3 & 2565.3 & 120.09 & 103.61 & 134.62 & $\mathrm{e}$ & $\mathrm{b}$ & $\mathrm{T}$ & $\mathrm{x} 1(0)$ & $\mathrm{x} 2(0)$ & 24.76 \\
\hline
\end{tabular}

Table 8: 8\% variation of model parameters

\begin{tabular}{|c|c|c|c|c|c|c|c|c|c|c|c|}
\hline$=\quad m p$ & $\mathrm{~b}$ & $\mathrm{e}$ & $\mathrm{x}_{1}(0)$ & $\mathrm{x}_{2}(0)$ & $\mathrm{T}$ & \multicolumn{5}{|c|}{ Order of sensitivity } & $\mathrm{E}_{\mathrm{S}}$ \\
\hline 1-norm & 1408.5 & 4134.6 & 3.32 & 3.31 & 29.35 & $\mathrm{e}$ & $\mathrm{b}$ & $\mathrm{T}$ & $\mathrm{x} 1(0)$ & $\mathrm{x} 2(0)$ & 1249 \\
\hline 2-norm & 1318.1 & 4039.7 & 14.33 & 16.44 & 39.52 & $\mathrm{e}$ & $\mathrm{b}$ & $\mathrm{T}$ & $\mathrm{x} 2(0)$ & $\mathrm{x} 1(0)$ & 281.8 \\
\hline infinity-norm & 1403.7 & 2250.7 & 115.78 & 100.98 & 132.33 & $\mathrm{e}$ & b & $\mathrm{T}$ & $\mathrm{x} 1(0)$ & $\mathrm{x} 2(0)$ & 22.29 \\
\hline
\end{tabular}

Table 9: 9\% variation of model parameters

\begin{tabular}{|l|l|l|l|l|l|l|l|l|l|l|l|}
\hline $\begin{array}{l}\mathrm{mp} \\
\mathrm{mn}\end{array}$ & $\mathrm{b}$ & $\mathrm{e}$ & $\mathrm{x} \mathrm{x}_{1}(0)$ & $\mathrm{x} 2(0)$ & $\mathrm{T}$ & \multicolumn{3}{|l|}{ Order of sensitivity } & \multicolumn{2}{l|}{$\mathrm{E}_{\mathrm{S}}$} \\
\hline 1-norm & 1252.2 & 3675.9 & 3.17 & 3.1601 & 26.02 & $\mathrm{e}$ & $\mathrm{b}$ & $\mathrm{T}$ & $\mathrm{x} 1(0)$ & $\mathrm{x} 2(0)$ & 1163 \\
\hline 2-norm & 1161.6 & 3580.5 & 13.73 & 15.86 & 37.12 & $\mathrm{e}$ & $\mathrm{b}$ & $\mathrm{T}$ & $\mathrm{x} 2(0)$ & $\mathrm{x} 1(0)$ & 260.8 \\
\hline infinity-norm & 1246.2 & 2006 & 111.82 & 98.43 & 130.0 & $\mathrm{e}$ & $\mathrm{b}$ & $\mathrm{T}$ & $\mathrm{x} 1(0)$ & $\mathrm{x} 2(0)$ & 20.38 \\
\hline
\end{tabular}

Table 10: $\quad 10 \%$ variation of model parameters

\begin{tabular}{|l|l|l|l|l|l|l|l|l|l|l|l|l|}
\hline $\begin{array}{l}\mathrm{mp} \\
\mathrm{mn}\end{array}$ & $\mathrm{b}$ & $\mathrm{e}$ & $\mathrm{x}(0)$ & \multicolumn{2}{l|}{$\mathrm{x}_{2}(0)$} & $\mathrm{T}$ & \multicolumn{3}{|l|}{ Order of sensitivity } & \multicolumn{2}{l|}{$\mathrm{E}_{\mathrm{S}}$} \\
\hline 1-norm & 1127.1 & 3308.8 & 3.03 & 3.02 & 23.35 & $\mathrm{e}$ & $\mathrm{b}$ & $\mathrm{T}$ & $\mathrm{x} 1(0)$ & $\mathrm{x} 2(0)$ & 1093 \\
\hline 2-norm & 1036.5 & 3213.1 & 13.17 & 15.31 & 35.06 & $\mathrm{e}$ & $\mathrm{b}$ & $\mathrm{T}$ & $\mathrm{x} 2(0)$ & $\mathrm{x} 1(0)$ & 243.8 \\
\hline infinity-norm & 1120 & 1810.2 & 108.17 & 95.99 & 127.87 & $\mathrm{e}$ & $\mathrm{b}$ & $\mathrm{T}$ & $\mathrm{x} 1(0)$ & $\mathrm{x} 2(0)$ & 18.86 \\
\hline
\end{tabular}




\section{Conclusion}

It is very clear from this study that the sensitivity values for the two intraspecific coefficients far outweigh the sensitivity values of the model parameter $\mathrm{T}$ and the two starting populations for these two interacting technologies. These novel contributions to knowledge clearly compliment other current sensitivity analysis results. For the purpose of parameter estimation, model validation and model prediction with minimal uncertainty, the parameters with higher sensitivity values will require further data collection with which to revalidate the model formulation. The two starting populations for these two interacting technologies should be considered as rough estimates in the sense that these two parameters provide small deviations between the two simulated data. We propose in our next study to fully justify the rationale of the least sensitivity philosophy in the theory of selecting and differentiating the most sensitive parameters from the least sensitive parameters.

\section{References}

[1] Bazykin A., Nonlinear Dynamics of Interacting Populations, World Scientific Series on Nonlinear Science, Series A, Vol 11, Leon Chua, ed., World Scientific, New Jersey, 1998

[2] Kumar U. and Kumar V., Technological Innovation Diffusion: The Proliferation of Substitution Models and Easing the User's Dilemma, IEEE Transactions on Engineering Management 39(2), 158-168 (1992).

[3] Young P., Technological Growth Curves, A Competition of Forecasting Models, Technological Forecasting and Social Change 44, 375-389 (1993)

[4] Bhargava S. C., Generalized Lotka-Volterra Equations and the Mechanism of Technological Substitution, Technological Forecasting and Social Change 35, 319-326 (1989)

[5] S. A. Morris, David Pratt, Analysis of the Lotka-Volterra Competition Equations as a Technological Substitution Model. Technological Forecasting and Social change 70(2003) 103-133.

[6] E. N. Ekaka-a, Computational and Mathematical Modelling of Plant Species Interactionsin a Harsh Climate, PhD Thesis, Department of Mathematics, The University of Liverpool and The University of Chester, United Kingdom, 2009. 